
THU0665

PREVALENCE OF RHEUMATIC DISEASES IN COLOMBIA: AN APPROACH FROM MINISTRY OF HEALTH AND SOCIAL PROTECTION DATA (SISPRO)

Daniel G. Fernández-Ávila ${ }^{1}$, Santiago Bernal-Macias ${ }^{2}$, Diana Rincón ${ }^{3}$, Juan Gutiérrez ${ }^{1}{ }^{1}$ Pontificia Universidad Javeriana - Hospital Universitario San Ignacio, Internal Medicine - Rheumatology, Cra 7 No. 40-62, Colombia; ${ }^{2}$ Pontificia Universidad Javeriana - Hospital Universitario San Ignacio, Internal Medicine, Bogotá, Colombia; ${ }^{3}$ Universidad Militar Nueva Granada - Hospital Militar Central, Rheumatology, Carrera 5 No 49-00, Colombia

Background: The ministry of health and social protection of Colombia uses a system named SISPRO as a tool to establish the basic information of the health system. This information is public and available for anyone to search. We analyze the prevalence and specific characteristics of patients with rheumatic diseases registered in colombian health system between 2012 to 2016.

Objectives: To establish the prevalence and basic epidemiological characteristics of the main rheumatic diseases in Colombia

Methods: This is a descriptive epidemiological study using the International Statistical Classification of Diseases and Related Health Problem (CDI), as keywords for each rheumatic disease during the analysis of SISPRO data and National Statistical System (DANE) populations projections, as from the last census in Colombia to estimated prevalence of each disease.

Results: Colombia is a middle-income country with an estimated population of 49.834.240 habitants to 2018 according to 2005 census projections. Despite some limitations of SISPRO data, actually is the only official database of the government. We calculate the estimated prevalence and number of patients with some rheumatic diseases (table 1), confirming that autoimmune diseases are more frequent in woman, and surprisingly, spondyloarthritis (ankylosing, psoriasis and inflammatory bowel disease) are also discreetly more frequent in woman population.

\begin{tabular}{lccc}
\hline & Total cases & Prevalence (\%) & Ratio woman: man \\
\hline Rheumatoid arthritis & 248.995 & 0,520 & $4,71: 1$ \\
Ankylosing spondylitis & 84.356 & 0,177 & $2,71: 1$ \\
Gout & 70.881 & 0,149 & $0,25: 1$ \\
Sjögren syndrome & 58.680 & 0,123 & $4,63: 1$ \\
Systemic lupus erythematosus & 41.804 & 0,088 & $4,17: 1$ \\
Polymyalgia rheumatic & 35.331 & 0,070 & $6,69: 1$ \\
Sjögren syndrome & 10.473 & 0,022 & $3,22: 1$ \\
Inflammatory miopathy & 8.498 & 0,018 & $1,76: 1$ \\
Psoriatic arthritis & 1.670 & 0,004 & $1,32: 1$ \\
Granulomatosis with polyangiitis & 750 & 0,002 & $7,44: 1$ \\
Beçhet Disease & 523 & 0,001 & $2,15: 1$ \\
Churg Strauss disease (EGPA) & 186 & 0,0001 & $2,24: 1$ \\
\hline
\end{tabular}

Table 1. Prevalence of rheumatic diseases in Colombia

Conclusion: Epidemiological and prevalence information of rheumatic diseases in Colombia is presented. The data found in the present study are concordant with epidemiological studies in other countries.

Disclosure of Interests: : None declared

DOI: 10.1136/annrheumdis-2019-eular.6955

\section{THU0666 SERIOUS/AT LEAST MODERATE INFECTIONS IN PATIENTS WITH JUVENILE IDIOPATHIC ARTHRITIS ON SYNTHETIC AND BIOLOGIC DRUGS FROM THE PHARMACHILD REGISTRY}

Gabriella Giancane, Joost F. Swart, Nikolay Tzaribachev, Nadina Rubio, Ruben Cuttica, Ingrida Rumba-Rozenfelde, Wafaa Mohammed Saad Suwairi, Calin Lazar, Yosef Uziel, Albena Telcharova, Tadej Avcin, Angela Minaici, Claudio Len, Stella Maris Garay, Alina Boteanu, Angela Pistorio, Nico Wulffraat, Nicolino Ruperto, Paediatric Rheumatology International Trials Organisation (PRINTO). IRCCS Istituto Giannina Gaslini, Clinica Pediatrica e Reumatologia, PRINTO, Genoa, Italy

Background: Infections are a major concern for patients affected by juvenile idiopathic arthritis (JIA) treated with immunosuppressive therapy. Evidence is inconsistent as to whether the start of synthetic or biological disease modifying anti-rheumatic drugs (DMARDs) is associated with an increased risk of serious and at least moderate infection.

Objectives: To determine whether the addition of a TNF inhibitor (TNFi) to methotrexate (MTX) may increase the risk of serious and at least moderate infections in JIA patients included in the Pharmachild registry. (1)
Methods: Serious and at least moderate infections were analysed in JIA patients, enrolled in the Pharmachild registry at September 30th, 2018, who started as first drug with MTX. We divided patients in 3 treatment groups: "MTX alone", in which patients had received MTX as the only drug all over their history; "MTX Start", in which patients had received MTX as first drug; "MTX+TNFi" for those patients who received a TNFi in addition to MTX after a period of "MTX Start". All the 3 groups were pure, since they received only these drugs. We considered initial infections as related to the treatment if the infection occurred in the drug period or within 90 days after treatment stop.(2) For the group "MTX Start", infection was related to treatment if occurring in the drug period stopped as soon as the second drug was introduced. For the group "MTX+TNFi", we considered all the possible correlations between start and end dates of the two drugs, including the time lag of 90 days after any treatment stop. If the interval between two drugs was shorter than 90 days, treatment was considered continuous. Crude rates (number of infections divided by drug exposure, excluding off-drug periods) and true incidence rates (number of first infections divided by the time lag between first drug administration and the date of the infection if the patient experienced the infection, the last Pharmachild visit if the patient didn't experience the event) were calculated.

Results: We enrolled in Pharmachild a total of 8061 patients who experienced 1686 infections. We excluded 41 patients who had infections before any treatment start. Of the final number of 8020 patients, we considered: 1226 patients in the group "MTX alone", 3128 in the group "MTX start" and 1026 in the group "MTX+TNFi". 7.7\% of the patients in the "MTX alone" group, $2.7 \%$ of the patients in the "MTX Start" group and $7.0 \%$ of the patients in the "MTX+TNFi" group experienced at least one infection. Crude rates of infections per 1000 person-years resulted: 48.0 for the group "MTX alone", 22.0 for "MTX Start", 74.0 for "MTX +TNFi". Incidence rates per 1000 person-years were: 32.0 for the group "MTX alone", 17.0 for "MTX Start", 59.5 for "MTX+TNFi". The percentage of drug exposure on the patient follow-up was variable among the 3 treatment groups (from $15.6 \%$ for the "MTX+TNFi" group to $51.5 \%$ for the "MTX alone" group)

Conclusion: Pharmachild showed, through the analysis of pure treatment groups, that the addition of the anti-TNF biologic to MTX even triples the incidence rate of infections.

\section{REFERENCES:}

[1] Swart, et al. Arthritis Res Ther. 2018;20:285; (2) Dixon WG, et al. Arthritis\&amp;Rheumatism 56:2896-2904.

Disclosure of Interests: Gabriella Giancane: None declared, Joost F. Swart: None declared, Nikolay Tzaribachev: None declared, Nadina Rubio None declared, Ruben Cuttica Grant/research support from: Roche, Pfizer, Lilly, Bristol Myers Squibb, Novartis, Sanofi Aventis, UCB, Janssen., Consultant for: Roche, Pfizer, Lilly, Bristol Myers Squibb, Novartis, Sanofi Aventis, UCB, Janssen., Speakers bureau: Roche, Pfizer, Lilly, Bristol Myers Squibb, Novartis, Sanofi Aventis, UCB, Janssen., Ingrida RumbaRozenfelde: None declared, Wafaa Mohammed Saad Suwairi: None declared, Calin Lazar: None declared, Yosef Uziel: None declared, Albena Telcharova: None declared, Tadej Avcin: None declared, Angela Minaici: None declared, Claudio Len: None declared, Stella Maris Garay: None declared, Alina Boteanu: None declared, Angela Pistorio: None declared, Nico Wulffraat: None declared, Nicolino Ruperto Grant/research support from: The Gaslini Hospital, where NR works as full-time public employee, has received contributions (> 10.000 USD each) from the following industries in the last 3 years: BMS, Eli-Lilly, GlaxoSmithKline, F Hoffmann-La Roche, Janssen, Novartis, Pfizer, Sobi. This funding has been reinvested for the research activities of the hospital in a fully independent manner, without any commitment with third parties., Consultant for: Received honoraria for consultancies or speaker bureaus $(<10.000$ USD each) from the following pharmaceutical companies in the past 3 years: Ablynx, AbbVie, Astrazeneca-Medimmune, Biogen, Boehringer, Bristol-Myers Squibb, Eli-Lilly, EMD Serono, GlaxoSmithKline, Hoffmann-La Roche, Janssen, Merck, Novartis, Pfizer, R-Pharma, SanofiServier, Sinergie, Sobi and Takeda., Speakers bureau: Received honoraria for consultancies or speaker bureaus (< 10.000 USD each) from the following pharmaceutical companies in the past 3 years: Ablynx, AbbVie, Astrazeneca-Medimmune, Biogen, Boehringer, Bristol-Myers Squibb, Eli-Lilly, EMD Serono, GlaxoSmithKline, Hoffmann-La Roche, Janssen, Merck, Novartis, Pfizer, RPharma, SanofiServier, Sinergie, Sobi and Takeda. DOI: 10.1136/annrheumdis-2019-eular.6773 